\title{
Left Atrial Myxoma as a Rare Cause of Cardiogenic Shock in Octagerians: Report of a Case and Review of the Literature
}

\author{
Stavros Daliakopoulos Dr.med Ph.D* , Andreas Tselios, Dimitrios Maragiannis, Kanellos Giakoumakis, \\ Konstantinos Konstantinou, Maria Stergiani, Athina Rammou and Sotirios Moraitis \\ Cardiac Surgery Department, Hellenic Army Hospital, Greece
}

Submission: December 27, 2016; Published: January 17, 2017

*Corresponding author: Stavros Daliakopoulos Dr. med Ph.D, Cardiac Surgeon, Joint Corps Armed Forces Cardiac Surgery Dpt. 401 Hellenic Army Hospital, Mesogion Aven. 138 \& Katechaki 11525, Athens, Hellas, Tel. +30 6947429559; Email: sdaliakopoulos@live.com

\section{Abstract}

Introduction: Cardiogenic Shock (CS) is a state of end-organ hypo perfusion due to cardiac failure. It occurs in 5\% to $8 \%$ of patients hospitalized with ST- elevation myocardial infarction (STEMI). Although myocardial infarction with left ventricle failure remains the most common cause of CS, it is crucial to exclude or / and identify rare pathologies that mimic this condition. Left atrial myxoma is the most common benign primary tumor of the heart, accounting for up to $50 \%$ of primary cardiac tumors. CS or even sudden cardiac death due to myxomas may result from either complete obstruction of the mitral valve orifice or MI resulting from coronary artery emboli.

Case Presentation: We report a patient admitted to our department because of syncopal episode and altered mental status due to a large left atrium myxoma. The patient was treated surgically, the myxoma was removed and the systemic manifestations of organ malperfusion were reversed.

Conclusion: Identifying myxoma as a rare pathology provoking CS in octageriansrequires a high index of suspicion and diagnosis can be sometimes elusive. Differential diagnosis of new onset cardiac dysrhythmias or even CS should include this infrequent noxiousness. Clinical icon varies from asymptomatic to causing severe morbidity and sudden death, with symptoms suggestive of different cardiac entities. Surgical removal remains simplex process offering curative treatment, an excellent prognosis and low recurrences rates.

\section{Introduction}

Cardiogenic shock was first defined as a rude unhinging of the machinery of life. A more recent clinical definition describes CS as decreased cardiac output and tissue hypoxia in the presence of adequate intravascular volume. The most common cause of CS is myocardial infarction with ST - segment elevation [1] whereas the incidence in unstable angina is about $2.9 \%$ and $2.1 \%$ in non-ST-elevation myocardial infarction [2]. CS leading to sudden deathis known to occur in patients with primary cardiac tumors (Table 1) and is estimated to constitute 0.01 to $0.005 \%$ of all sudden deaths [3]. Cardiac myxoma has been reported as early as 1953 by Madonia et. al. [4] as a rare cause of sudden cardiac death [4], but the first description of a left atrial myxoma is accredited to King in 1845 [5]. It arises from the endocardium as a lipidic cell mass embedded in a vascular myxoid stroma. Most myxomas are sporadic and the cause is largely unknown. Myxomas are the most common primary neoplasms of the heart comprising about $30-50 \%$. Approximately $75 \%$ are located in the left atrial cavity, $23 \%$ in the right atrial cavity and about $2 \%$ in the ventricular cavity $[6,7]$. The clinical presentation which primarily depend on the cardiac chamber where they occur, varies from asymptomaticincidental masses to serious lifethreatening cardiovascular complications and thus present as Achilles' heel for early diagnosis. Left atrial myxoma more often presents with symptoms and signs of obstruction of the lesser circulation.

Table 1: Primary Cardiac Tumors.

\begin{tabular}{|c|c|}
\hline Benign Tumors & Malignant Tumors \\
\hline Myxoma & Mesothelioma \\
\hline
\end{tabular}


Journal of Cardiology \& Cardiovascular Therapy

\begin{tabular}{|c|c|}
\hline Hamartoma & Sarcoma \\
\hline Rhabdomyoma & Lymphoma \\
\hline Fibroma & Paraganglioma \\
\hline Hemangioma & \\
\hline Lipoma & \\
\hline Dermoid Tumors & \\
\hline Papillary Fibroelastoma & \\
\hline
\end{tabular}

\section{Case Presentation}

A 79-year-old woman was admitted to our hospital because of a syncopal episode followed by altered mental status. The patient was at her usual state of health with a six-month history of exertional dyspnea managed as bronchial asthma, when she suddenly lost consciousness and vomited while walking. She was transferred by ambulance to the emergency department within 40 minutes after the onset of symptoms. On arrival, she said she did not have chest pain or headache, but she was unable to provide other history. On examination, she was lethargic, with periods of unresponsiveness. There was no sign of head trauma; the remainder of the examination was normal. A radiograph of the chest showed pulmonary vascular prominence with no evidence of edema, infiltrate or effusion. An electrocardiogram revealed sinus tachycardia with $\mathrm{ST}$ - segment elevation in $\mathrm{V}_{3}$ through $\mathrm{V}_{6}$. Tests for creatinine kinase and troponin $\mathrm{T}$ were negative. Transthoracic echocardiography showed hypokinesis of the anterior, septal, and apical walls of the left ventricle. Overall left ventricle systolic function was at the lower limit of the normal range. The left atrium was dilated. There was a large pedunculated mobile echodensity in the left atrium that was attached to the atrial septum (Figures $1 \& 2$ ). The mass was obstructing flow with a mean trans mitral gradient of $17 \mathrm{~mm} \mathrm{Hg}$, with a reduced stroke volume and moderate to severe pulmonary hypertension with an estimated right ventricular systolic pressure of $90 \mathrm{~mm}$ Hg. Subsequent transesophageal views revealed a mass $7 \mathrm{~cm} \mathrm{x}$ $3 \mathrm{~cm} \times 3.4 \mathrm{~cm}$ with its base attached to the interatrial septum. The mass was highly mobile with multiple frondlike elements. Color Doppler imaging showed no evidence of a patent foramen ovale. Magnetic resonance imaging (MRI) of the brain revealed no new infarcts. An emergency Interventional angiography performed prior surgical excision and approximately 12 hours after the onset of symptoms revealed an occlusive filling defect in the proximal portion of the circumflexus coronary artery. Balloon dilatation and DES implantation improved filling. The patient was intubated, a nasogastric tube was placed and moved to the operating room. Subsequently, surgical resection of the left atrial mass was performed via transatrial surgical approach and the atrial septum defect repaired with a homologue patch. The resected mass was $7 \mathrm{~cm} \times 3 \mathrm{~cm} \times 3.4 \mathrm{~cm}$, with an irregular frondlike surface (Figures $3 \& 4$ ). On microscopical examination, the mass also had the morphologic features of a cardiac myxoma.

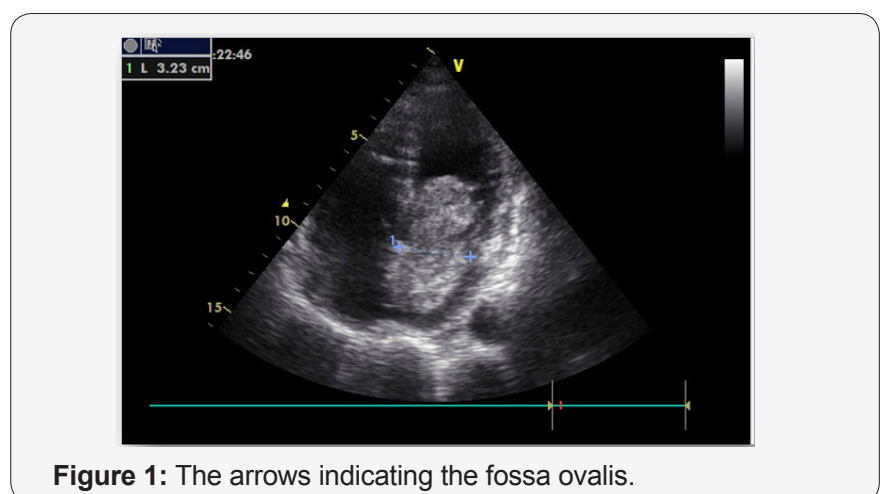

Figure 1: The arrows indicating the fossa ovalis.

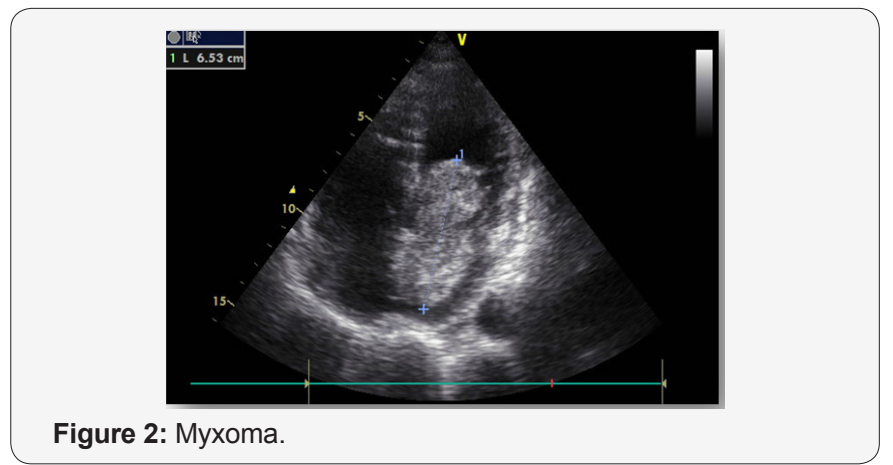

Figure 2: Myxoma.

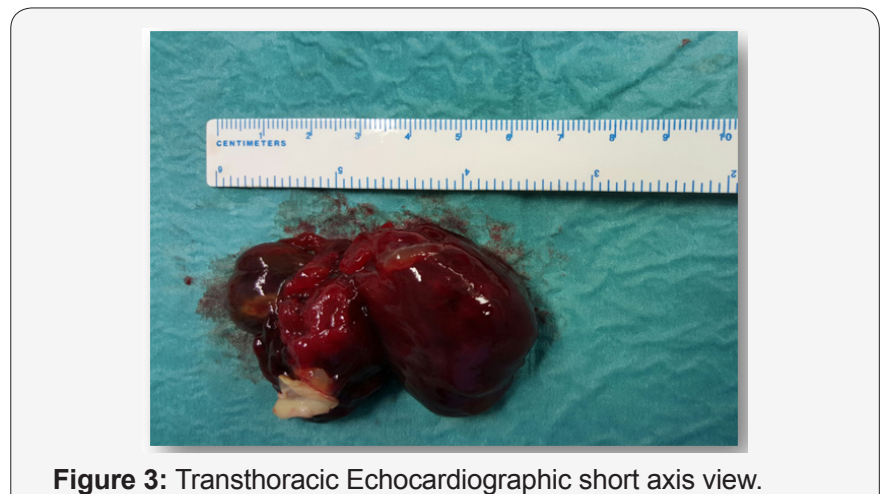

Figure 3: Transthoracic Echocardiographic short axis view. 


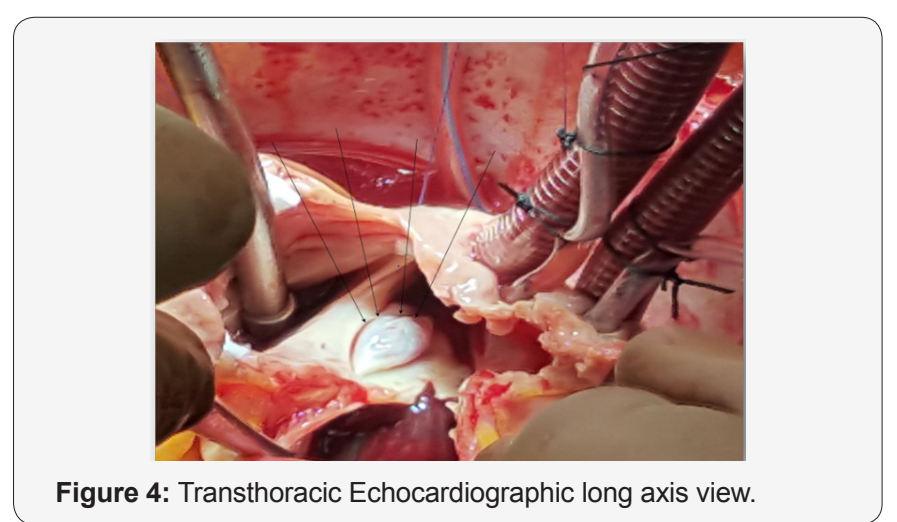

Immunohistochemistry showed that the cells were strongly positive for vimentin, CD34 and for calretinin (29 kDa calbindin), a calmodulin-like calcium -binding protein of unknown function. Normal endocardium and organizing thrombi do not strain for calretinin, whereas 80 to $100 \%$ of cardiac myxomas show strong straining for this marker [8]. These histologic features are diagnostic of cardiac myxoma $[8,9]$.

Postoperatively she was initially treated with heparin monitored three times per day, using the partial thromboplastin time (aPTT) and the dose was adjusted to attain the target $50-$ $60 \mathrm{sec}$. On $3^{\text {rd }}$ postoperative day she was set on apixaban (Eliquis $\left.{ }^{\circledR}\right) 2.5 \mathrm{mg}$ twice daily. The patient remained in the ICU for 1 day and discharged to home on $7^{\text {th }}$ postoperative day. The whole postoperative period was uneventful.

\section{Discussion}

The great majority of primary cardiac tumors are histologically benign. Although benign tumors of the heart are rare - autopsy studies suggest that the overall prevalence is between 0.001 and $0.25 \%$ of the population $[10,11]$ - it is estimated that they account for more than $75 \%$ of primary tumors of the heart. Although these tumors do not metastasize, they can have catastrophic effects due to impairment of cardiac structure and function, including the precipitation of arrhythmias or embolism. Cardiac myxoma is the most common benign primary tumor of the heart, accounting for up to $50 \%$ of primary cardiac tumors.

The majority of myxomas are solitary and occur in the left atrium, typically in the zone of the fossa ovalis [12], as in this case. It can be seen in patients between 3-83 years old, with the majority presenting in fifth decade of life and just few cases are mentioned presenting left atrial myxoma after the seventh decade. Is most commonly seen in women with $90 \%$ being solitary and pedunculated and $10 \%$ being familial, with an autosomal dominant pattern of inheritance [13] When multiple, recurrent, ventricular or familial myxomas are discovered, there is cause to consider the diagnosis of Carney's syndrome, a familial syndrome characterized by multiple neoplasms [14]. The clinical features of atrial myxoma vary, as well as the size, with most cases in literature referring to myxomas sized between 0.4 to $6,5 \mathrm{~cm}[15]$. Large tumors are related to atrial fibrillation.

Diagnosis is often incidental and by symptomatic myxomas challenging, as they often cause signs and symptoms that suggest other, more common, conditions. This is understandable, given the diverse array of signs and symptoms these patients experience. Myxomas symptoms include dizziness, syncope and dyspnea and are usually caused by intermittent obstruction of the mitral valve by a prolapsing mass. In up to $50 \%$ of cases, cytokine production by the tumor may result in fever, weight loss, arthralgias or myalgias or even Raynaud's phenomenon $[16,17]$. Obstructive symptoms appear at the $70 \%$ of patients with left atrial myxoma and constitutional infarction estimated between 10 - 45\%.Sudden cardiac arrest may be related with large myxomas and complete obstruction of the mitral or tricuspid valve orifices or myocardial infarction resulting from coronary artery embolism $[7,18]$. There are 19 cases published since 1950 regarding sudden cardiac death due to myxomas [19].

Embolization, systemic or pulmonary, is identified as the second most common manifestation that occurs in 30 to $40 \%$ of cases, whereas $35 \%$ on left sided myxomas [20] and may result from infected or uninfected thrombi on the tumor or from release of fragments of the tumor itself. Depending on the localization of the tumor emboli from left atrial myxomas cause a greater diversity of complications, ranging from cutaneous microinfarctions to transient ischemic attacks and acute stroke syndromes $[21,22]$.

Since myxomas develop within the heart, with the majority of originating in the left atrium it is not surprising that cardiac complications predominate and among them acutely decompensated heart failure is the most frequent presentation $[23,24]$.

Echocardiography was reported to be the definitive diagnostic modality. The sensitivity of transthoracic echocardiography is about $95 \%$ determine accurately the location, the size, the attachment and the mobility of the mass. Transesophageal echocardiography has nearly $100 \%$ sensitivity for cardiac myxoma. The tumor tissue manifests as spherical - pedunculated mass attached to the endocardial surface with hypoechoic areas [25].

Many cases required more than one diagnostic study, the most common of which was computed tomography scans that identified the mass incidentally and were subsequently confirmed with echocardiography. In more recent reports, MRI is increasingly mentioned as a modality to better characterize tumor location and involvement preoperatively. Differences in signal intensity between myocardium, tumor/thrombus is very helpful, especially with the use of contrast agent like GadoliniumDTPA [26-28]. A cine MRI sequence is a very sensitive technique to distinguish between an thrombus and a tumor, intra-cardiac or intravascular. 
Once the diagnosis of cardiac myxomas made, timely surgical resection is required to prevent complications and secure immediate and long-term excellent outcomes [22,23,24-29]. Operative mortality ranges from 0 to $3 \%$ and recurrence rates are between $1 \%$ and $3 \%$ for sporadic myxomas [30-33].

\section{Conclusion}

Myxomas are notoriously difficult to diagnose. The presentation is varied and may be vague and diagnosis is often delayed. The patients with cardiac myxomas often do not have any obvious clinical signs. Relative hypotension and mild tachycardia are most of the time present. The current tests of choice are echocardiography and cardiac MRI with gadolinium injection, which is useful to distinguish tumor from thrombus because tumors are typically enhanced with gadolinium, whereas thrombi are not. Therefore, myxoma should be considered in patients without traditional cardiac risk factors who present with progressive or acute dyspnea and clinical evidence of heart failure, especially if a new cardiac murmur is detected. Myxoma should always be on the differential for pulmonary embolism, pulmonary hypertension and embolic strokes. Treatment consists of prompt surgical excision.

\section{Consent}

Written informed consent was obtained from our patients for publication of this case report and any accompanying images. A copy of the written consent is available for review by the Editor-in-Chief of this journal.

\section{Authors' Contributions}

SID participated in sequence alignment, designing the case report and drafting the manuscript. AT participated in the design of the case report. KK participated in the design and culled relevant information. DM participated in the design of the case report, MS participated in the design of the case report, AR participated in the design of the case report, KG participated in the design of the case report, SM coordinated the preparation of the case report. All authors read and approved the final manuscript.

\section{References}

1. Holmes DR, Beger PB, Hochman JS, Granger CB, Thompson TD, et al. (1999) Cardiogenic shock in patients with acute ischemic syndromes with and without ST-segment elevation. Circulation 100(20): 20672073.

2. Hasdai D, Harrington RA, Hochman JS, Califf RM, Battler A, et al. (2000) Platelet glycoprotein IIb/ IIIa blockade and outcome of cardiogenic shock complicating acute coronary syndromes without persistent STsegment elevation. J Am Coll Cardiol 36(3): 685-692.

3. Cina SJ, Smialek JE, Burke AP, Virmani R, Hutchins GM (1996) Primary cardiac tumors causing sudden death: a review of the literature. Am J Forensic Med Pathol 17(4): 271-281.

4. Puff M, Taff ML, Spitz WU, Eckert WG (1986) Syncope and sudden death caused by mitral valve myxomas. Am J Forensic Med Pathol 7(1): 84-86
5. King TW (1845) On simple vascular growth in the auricle of the heart. Lancet 46(1155): 428-429.

6. Roberts WC (1997) Primary and secondary neoplasms of the heart. Am J Cardiol 80(5): 671-682.

7. Reynen K (1995) Cardiac Myxomas. N Eng J Med 333(24): 1610-1617.

8. Terracciano LM, Mhawech P, Suess K, D'Armiento M, Lehmann FS, et al. (2000) Calretinin as a marker for cardiac myxoma: diagnostic and histogenetic considerations. Am J Clin Pathol 114(5): 754-759.

9. Burke AP, Virmani R (1993) Cardiac myxoma: a clinicopathologic study. Am J Clin Pathol 100(6): 671-680.

10. Butany J, Nair V, Naseemuddin A, Nair GM, Catton C, et al. (2005) Cardiac tumors: diagnosis and management. Lancet Oncol 6(4): 219228.

11. Acebo E, Val-Bernal JF, Gomez-Roman JJ, Revuelta JM (2003) Clinicopathologic study and DNA analysis of 37 cardiac myxomas: a 28-year experience. Chest 123(5): 1379-1385.

12. VH Lee, H M Connolly, R D Brown Jr (2007) Central nervous system manifestations of cardiac myxoma. Arch Neurol 64(8): 1115 -1120.

13. Yap W, Bhattacharya K, Pathi V (2005) Left atrial myxoma in transplanted heart. Heart 91(6): e49.

14. (2002) Case records of the Massachusetts General Hospital (case 112002), N Engl J Med 346: 1152-1158.

15. Kalgi Modi, Prasanna Venkatesh, Sujata Agnani, Tanya Rowland, Pratap Reddy (2010) Sudden death in a patient with left atrial myxoma: report of two cases and review of literature. BJMP 3(2): 318.

16. Gradenc ML, Rosado Chris ML, Green CE, Burke AP Galvin JR (2002) Cardiac myxoma: Imaging features in 83 patients. Radiographics 22(3): $673-689$.

17. Lazaros G, Vavouranakis M, Vrachatis DA, Stefanadis C (2010) A 53 -years-old woman with recurrent transient ischemic attacks. Chest 138(4): 1004-1009.

18. Pucci A, Gagriaratto P, Zanini C, Pansini S, di Summa M, et al. (2000) Histopathologic Clinical Characterization of Cardiac Myxoma: review of 53 cases from a single institution. Am Heart J 140(1): 134-138.

19. Mendoza CE, Rosado MF, Bernal L (2001) The role of interleukin 6 in cases of cardiac myxoma: clinical features, immunologic abnormalities and a possible role of recurrence. Tex Heart Inst J 28: 3-7.

20. Kuon E, Kreplin M, Wess W, Dahm JB (2004) The challenge presented by right atrial myxoma. Herz 29(7): 702-709.

21. Ekinci EI, Donnan GA (2004) Neurological manifestations of cardiac myxoma: a review of the literature and report of cases. Intern Med J 34(5): 243-249.

22. Keeling IM, Oberwalder P, Anelli-Monti M, Schuchlenz H, Demel U, et al. (2002) Cardiac myxomas: 24 years of experience in 49 patients. Eur J Cardiothoracic Surg 22(6): 971-977.

23. Jelic J, Milicic D, Alfirevic I, Anic D, Baudoin Z, et al. (1996) Cardiac myxoma: diagnostic approach, surgical treatment and follow up. A twenty years experience. J Cardiovasc Surg (Torino) 37(6 suppl. 1): 113-117.

24. Engberding R, Daniel WG, Erbel R, W Kasper, C Lestuzzi, et al. (1993) The European Cooperative Study Group: Diagnosis of heart tumors by transoesophageal echocardiography: a multicenter study in 154 patients. Eur Heart J 14(9): 1223-1238.

25. Bakaeen FG, Reardon MJ, Coselli JS, Miller CC, Howell JF, et al. (2003) Surgical outcome in 85 patients with primary cardiac tumors. Am J Surg 186(6): 641-647. 
26. Thakur AK, Thakur S (2003) Infection and cardiac tumors: evaluation through imaging. Medicine Update. Association of physicians of India 13: 575-582.

27. Alison W Frizell, George L Higgins III (2014) Cardiac myxoma as mimic: a diagnostic challenge. Am J Emerg Med 32(11): 1399-1404.

28. Percell RL Jr, Henning RJ, Siddique Patel M (2003) Atrial Myxoma: Case report and review of the literature. Heart Dis 5(3): 224-230.

29. Bhan A, Mehrotra R, Choudhary SK, Sharma R, Prabhakar D, et al. (1998) Surgical experience with intracardiac myxomas: long-term follow up. Ann Thorac Surg 66(3): 810-813.
30. Centofanti P, Di Rosa E, Deorsola L, Dato GM, Patane F, et al. (1999) Primary cardiac tumors: early and late results of surgical treatment in 91 patients. Ann Thorac Surg 68(4): 1236-1241.

31. Selakne C, Amahzoune B, Chavanis N, Raisky O, Robin J, et al. (2003) Changing management of cardiac myxoma based on a series of 40 cases with long-term follow-up. Ann Thorac Surg 76(6): 1935-1938.

32. Miittle s, Makaryus AN, Boutis L, Hartman A, Rosman D, et al. (2005) Right sided myxoma. J Am Soc Echocardiogr 18(6): 695.

33. S Bjessmo, T Ivert (1997) Cardiac myxoma: 40 years' experience in 63 patients. Ann Thorac Surg 63(3): 697-700.
Your next submission with Juniper Publishers will reach you the below assets

- Quality Editorial service

- Swift Peer Review

- Reprints availability

- E-prints Service

- Manuscript Podcast for convenient understanding

- Global attainment for your research

- Manuscript accessibility in different formats ( Pdf, E-pub, Full Text, Audio)

- Unceasing customer service

Track the below URL for one-step submission https://juniperpublishers.com/online-submission.php 